КОФ-413

\title{
СВЯЗЬ ОСОБЕННОСТЕЙ ЭМОЦИОНАЛЬНО-ЛИЧНОСТНОЙ СФЕРЫ С УРОВНЕМ ЭМОЦИОНАЛЬНОГО ВЫГОРАНИЯ РАБОТНИКОВ ДОШКОЛЬНОГО УЧРЕЖДЕНИЯ С РАЗНЫМ СТАЖЕМ РАБОТЫ
}

Крючкова Анна Сергеевна

к.П.н., доцент

\section{Дзюбина Наталья Геннадьевна}

магистрант 3 курса направления 37.04.01 Психология

профиль «Клиническая психология»

ФГБОУ ВО «Донской государственный технический университет»

\begin{abstract}
Аннотация: В статье мы рассматриваем связь профессионального выгорания и эмоционального интеллекта работников дошкольного учреждения. В исследовании приняли участие 80 работников, женщины в возрасте от 20 до 58 лет. Группа исследуемых была разделена по основанию стажа работы: от 0,5 до 3 лет, от 3 до 10 лет, более 10 лет. В ходе исследования были использованы методики: опросник «Профессиональное выгорание» (К. Маслач и С. Джексон в адаптации Н.Е. Водопьяновой и Е.С. Страченковой), опросник ЭмИн Д.В. Люсина; и методы математической статистики: описательная статистика, Н-критеррий Крусклла-Уолис, корреляционный метод r-Спирмена. Результаты исследования позволили выявить взаимосвязи между показателями профессионального выгорания и шкалами методики ЭмИн Люсина. В ходе корреляционного анализа установлено, что показатель Редукция профессионализма является ключевым, оказывающим воздействие на эмоциональный интеллект работников независимо от стажа работы.
\end{abstract}

Ключевые слова: Профессиональное выгорание, эмоциональный интеллект, педагоги, работники ДОУ, компетентность, деперсонализация, редукция профессионализма, эмоциональное истощение. 


\title{
THE RELATIONSHIP OF THE FEATURES OF THE EMOTIONAL AND PERSONAL SPHERE WITH THE LEVEL OF EMOTIONAL BURNOUT OF PRESCHOOL WORKERS WITH LONG WORK EXPERIENCE
}

\section{Kryuchkova Anna Sergeevna Dzyubina Natalia Gennadievna}

\begin{abstract}
In the article we consider the connection between professional burnout and emotional intelligence of preschool workers. The study involved 80 employees, women aged 20 to 58 years. The group of subjects was divided on the basis of work experience: from 0.5 to 3 years, from 3 to 10 years, more than 10 years. In the course of the study, the following methods were used: the questionnaire "Professional burnout" (K. Maslach and S. Jackson in the adaptation of N.E. Vodopyanova and E.S. Strachenkova), the questionnaire of EmIn D.V.Lyusin; and methods of mathematical statistics: descriptive statistics, the H-criterion of Krusklla-Walis, the correlation method of r-Spearman. The results of the study revealed the relationship between the indicators of professional burnout and the scales of the EmIn Lyusin methodology. In the course of the correlation analysis, it was found that the Reduction of professionalism is a key indicator that affects the emotional intelligence of employees regardless of work experience.
\end{abstract}

Key words: Professional burnout, emotional intelligence, teachers, preschool workers, competence, depersonalization, reduction of professionalism, emotional exhaustion.

Профессиональная деятельность работников ДОУ отличается эмоциональной и психологической напряженностью, наличием сложных ситуаций в образовательной деятельности, противоречий между профессиональными задачами и возможностью их достижения. [8] Современный педагог в процессе труда сталкивается со стресс-факторами и конфликтогенами, которые негативно сказываются на самочувствии и здоровье педагога. Как показывают последние исследования, от психологического здоровья работника зависит уровень воспитанности и психологического благополучия воспитанников. [11] Современные исследователи связывают психологическое здоровье педагога с таким явлением как эмоциональное выгорание. Термин «эмоциональное выгорание» (англ.: burnout) был предложен в 1974 г. американским психиатром 
H. Freudenberger. [16] «Выгорание» было описано им как истощение вследствие резко завышенных требований к собственным ресурсам и силам. Сегодня синдром эмоционального выгорания в исследованиях отечественных и зарубежных ученых представлен как многофакторный процесс, включающий взаимодействие стресса, особенностей ЦНС личности, производственной среды и др. [12] В.В. Бойко

выделяет внутренние (индивидуально-психологические особенности) и внешние (организационные) факторы развития эмоционального выгорания. [1] Исследователи A. Pines и E. Aronson, главной причиной выгорания является неудачный поиск смысла жизни в профессиональной сфере. [15] В 1986 г. американские ученые C. Maslach и S. Jackson выделили три основные признака синдрома эмоционального выгорания (СЭВ): эмоциональную истощенность, деперсонализацию (дегуманизация по отношению к объектам своей деятельности) и редукцию профессиональных достижений. [13]

Способность установить и поддерживать адекватный контакт с воспитанниками и учащимися, распознавать и идентифицировать их переживания, регулировать свое эмоциональное состояние и контролировать экспрессию является одной из важнейшей компетентности современного педагога. Эмоциональная компетентность воспитателей позволяет ему создать благоприятную атмосферу в группе дошкольников и доверительные отношения с детьми и сотрудниками. Именно поэтому актуальным становится изучение профессионального выгорания во взаимосвязи с эмоциональным интеллектом.

Внимание исследователей к эмоциональному интеллекту (ЭИ) как совокупности ментальных способностей к пониманию собственных эмоций и эмоций других людей, и к управлению эмоциональной сферой - обусловлено тем, что он является предпосылкой просоциального и иного позитивного поведения, и его развитие оптимизирует межличностные взаимодействия. Эмоциональный интеллект понимается как способность осознавать отношения личности, представленные в эмоциях и управлять эмоциональной сферой на основе принятия решений (D. Goleman, P. Salovey, J. D. Mayer, N. Hall и др.. [4] Эмоциональный интеллект - это способность человека управлять самим собой и другими людьми. Он включает самосознание, контроль импульсивности, настойчивость, уверенность, самомотивацию, 
эмпатию и социальную ловкость. Эмоциональный интеллект является социальным эквивалентом общего интеллекта. [9]

По мнению ряда исследователей, эмоциональный интеллект может стать ресурсом преодоления синдрома профессионального выгорания. [10] Высокий уровень ЭИ, по мнению Р.Г. Макфарланда, позволяет снизить интенсивность негативных эмоций и предотвратить развитие эмоционального истощения, которое часто развивается в результате длительного переживания индивидом отрицательных эмоций. [14]

На сегодняшний день активно проводятся исследования взаимосвязи профессионального выгорания и эмоционального интеллекта сотрудников различных сфер деятельности. Несмотря на большое количество работ по данной теме наблюдается сравнительный дефицит исследований профессионального выгорания в связи с эмоциональным интеллектом сотрудников ДОУ с разным стажем педагогической деятельности. Этим обусловлен интерес к данной тематике.

Цель исследования состояла в изучении связи особенностей эмоционально-личностной сферы с уровнем эмоционального выгорания работников дошкольного учреждения с разным стажем работы.

Предмет исследования: связь особенностей эмоционально-личностной сферы с уровнем эмоционального выгорания работников дошкольного учреждения с разным стажем работы.

Объектом исследования выступили работники МБ ДОУ.

Исследование проведено в Муниципально бюджетных дошкольных образовательных учреждениях г. Батайска Ростовской области. В исследовании приняли участие 80 работников дошкольных учреждений, все женщины в возрасте от 20 до 58 лет. Стаж работы в дошкольных учреждениях от 6 месяцев до 38 лет. Выборка была разделена на три группы. В первую группу вошли работники со стажем работы до трех лет (40\% испытуемых), вторую группу составили работники со стажем работы от четырех до десяти лет (27\% участников исследования); 33\% работники со стажем работы в ДОУ вошли в третью группу.

Гипотеза исследования: вероятно существует различие в связях эмоционально-личностной сферы с уровнем эмоционального выгорания работников дошкольного учреждения с разным стажем работы.

В исследовании использовались следующие методики: опросник Профессиональное выгорание, разработанный Н.Е. Водопьяновой и Е.С. Страченковой на основе модели К. Маслач и С. Джексон, позволяющий 
определить уровень профессионального выгорания сотрудников (Водопьянова, 2013), опросник ЭмИн Д.В. Люсина, выявляющий особенности развития внутриличностного и межличностного эмоционального интеллекта (Люсин, 2009). Опросник Н.Е. Водопьяновой и Е.С. Страченковой содержит 22 утверждения о чувствах и переживаниях, связанных с выполнением рабочей деятельности. Он состоит из трех субшкал: Эмоциональное истощение, Деперсонализация, Редукция профессиональных достижений. Ответы оцениваются по 7-балльной шкале и варьируют от «никогда» (0 баллов) до «всегда» (6 баллов). В исследовании использовалась версия опросника для коммерческого персонала (Водопьянова, 2013).

Опросник ЭмИн оценивает межличностный и внутриличностный эмоциональный интеллект, которые, в свою очередь, включают в себя два параметра: управление эмоциями и понимание эмоций. Таким образом, «Межличностный эмоциональный интеллект» (МЭИ) включает в себя понимание чужих эмоций и управление эмоциями других людей, в то время как «Внутриличностный эмоциональный интеллект» (ВЭИ) - понимание своих эмоций и управление ими. «Понимание эмоций» (ПЭ) - способность к пониманию своих и чужих эмоций. «Управление эмоциями» (УЭ) способность к управлению как своими, так и чужими эмоциями (Люсин, 2009).

Результаты исследования

Профессиональное выгорание работников с разным стажем работы

На (рис. 1) представлены средние значения по шкалам профессионального выгорания у респондентов с разным стажем работы. Результаты исследования показывают, что у работников со стажем работы более 10 лет значительно выше значения по показателям Эмоциональное выгорание, Деперсонализация и Редукция профессионализма.

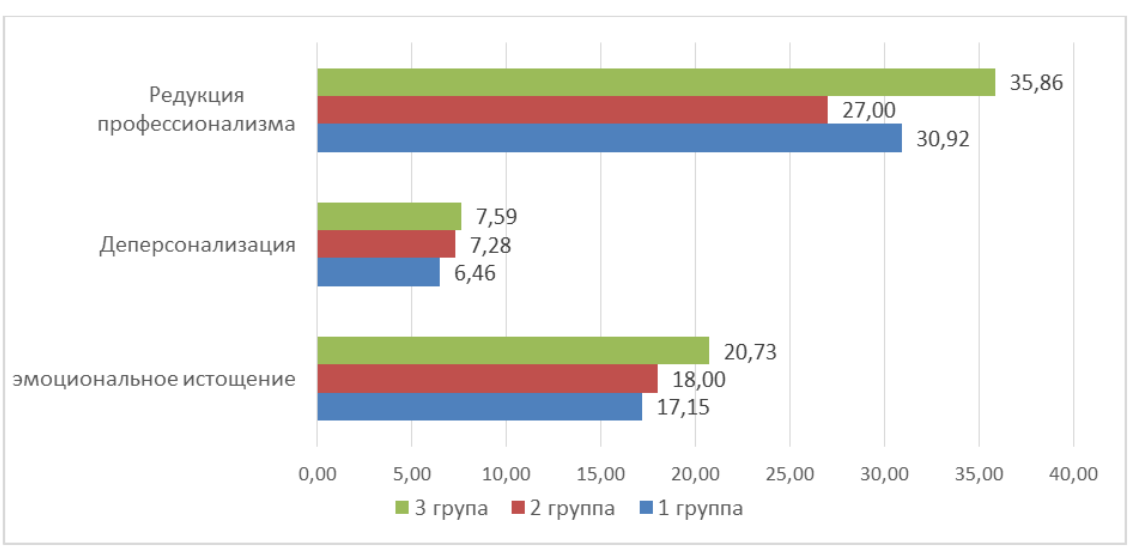

Рис. 1. Исследование профессионального выгорания у работников с разным стажем работы 
С целью изучения различий в уровне профессионального выгорания и выраженности эмоционального интеллекта был проведен статистический анализ методом Н-критерий Крускалла-Уолиса. Данные математической статистики представлены в (табл. 1).

Таблица 1

Результаты статистического анализа различий профессионального выгорания работников с разным стажем работы

\begin{tabular}{|c|c|c|c|}
\hline $\begin{array}{c}\text { Методика } \\
\text { исследования }\end{array}$ & Шкалы методики & Хи-квадрат & $\mathrm{p}$ \\
\hline \multirow{2}{\text{Профессиональное}}{$\begin{array}{c}\text { Эмоциональное } \\
\text { истощение }\end{array}$} & 1,516 &, 469 \\
\cline { 2 - 3 } $\begin{array}{c}\text { Вогорание (Н.Е. } \\
\text { Страченянов, Е.С. }\end{array}$ & Деперсонализация &, 519 &, $\mathbf{0 1 2}$ \\
\cline { 2 - 4 } & $\begin{array}{c}\text { Редукция } \\
\text { профессионализма }\end{array}$ & 8,898 & $\mathbf{2 7 2}$ \\
\hline
\end{tabular}

Таким образом, можно на статистически достоверном уровне утверждать, что работники 3 группы (стаж работы более 10 лет) значительно отличаются от работников со стажем работы до 10 лет по показателю Редукция профессионализма. Полученные результаты позволяют говорить о том, что работники 3 группы склонны более положительно оценивать свои профессиональные и личностные качества, чем работники 2 группы. Полученный результат можно объяснить большим опытом работы, накопленных специальных педагогических умений и навыков, профессиональным мастерством работников со стажем работы более 10 лет.

Специалисты со стажем работы от 3 до 10 лет менее удовлетворены своими профессиональными способностями, склонны к критичности своих действий и результатов труда, они в большей степени склонны облегчить или сократить количество профессиональных обязанностей, связанных с эмоциональными затратами. Возможно, это связано с тем, что еще не сложились стратегии и стиль профессиональной деятельности, нехватка профессионального опыта и компетентности.

Эмоциональный интеллект работников с разным стажем работы. 
На (рис. 2) представлены результаты исследования эмоционального интеллекта (опросник Д.В. Люсина). На (рис. 2) представлены результаты исследования ЭИ у работников с разным стажем работы.

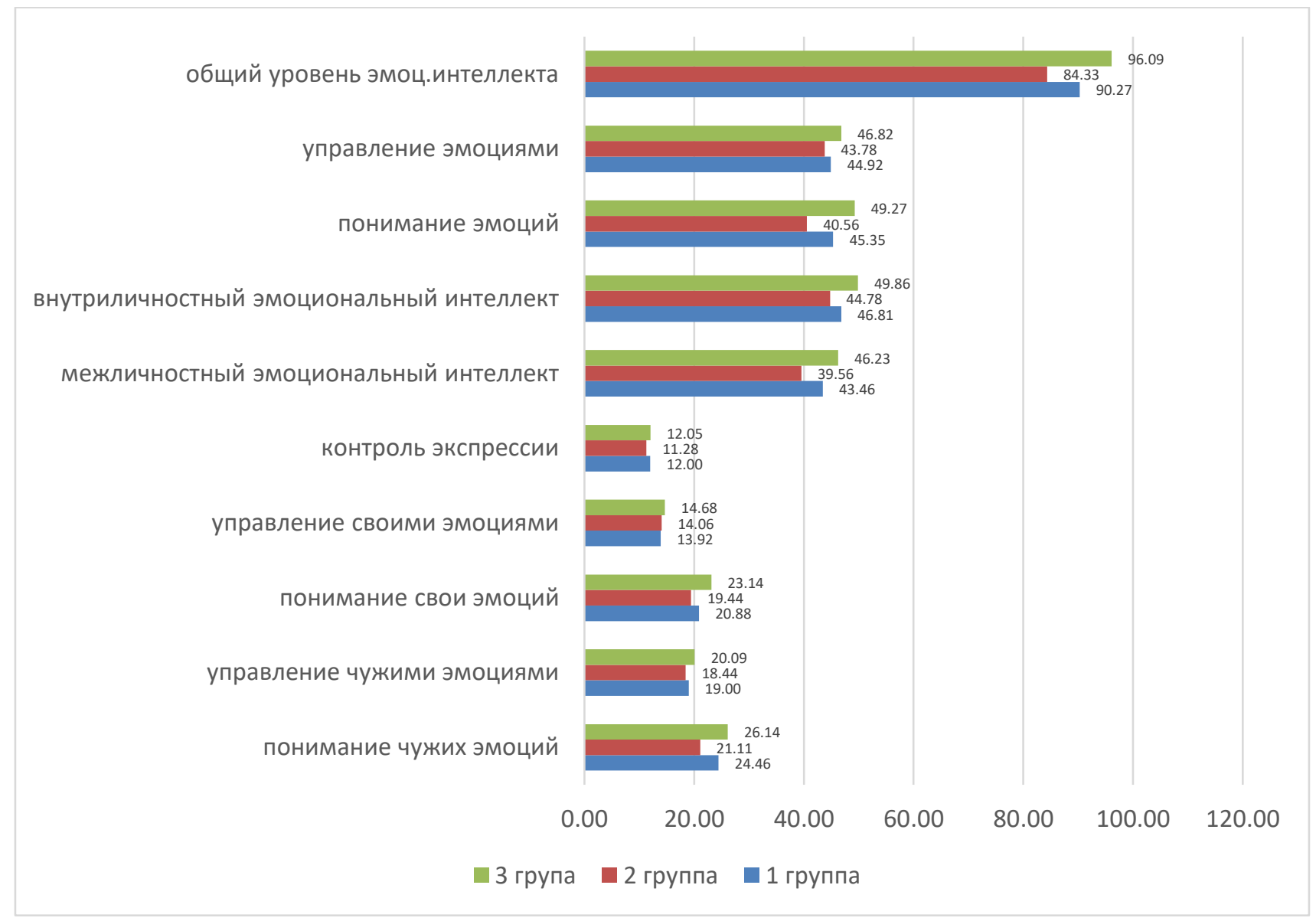

\section{Рис. 2. Исследование эмоционального интеллекта у работников с разным стажем работы}

В ходе исследования установлено, что у работников со стажем работы более 10 лет показатели по шкалам выше, чем в остальных группах. Низкие показатели по шкалам выявлены в группе работников со стажем работы от 3 до 10 лет.

Для выявления различий в выраженности эмоционального интеллекта был проведен статистический анализ методом Н-критерий Крускалла-Уолиса. Данные математической статистики представлены в (табл. 2). 
Таблица 2

Результаты статистического анализа различий эмоционального интеллекта работников с разным стажем работы

\begin{tabular}{|c|c|c|c|}
\hline $\begin{array}{c}\text { Методика } \\
\text { исследования }\end{array}$ & Шкалы методики & Хи-квадрат & $\mathrm{p}$ \\
\hline \multirow{10}{*}{$\begin{array}{c}\text { Опросник ЭмИн } \\
\text { (Д.В. Люсин) }\end{array}$} & $\begin{array}{c}\text { Понимание чужих } \\
\text { эмоций }\end{array}$ & 7,854 & ,020 \\
\hline & $\begin{array}{c}\text { Управление чужими } \\
\text { эмоциями }\end{array}$ & 2,999 & ,223 \\
\hline & $\begin{array}{c}\text { Понимание своих } \\
\text { эмоций }\end{array}$ & 6,616 & ,037 \\
\hline & $\begin{array}{c}\text { Управление своими } \\
\text { эмоциями }\end{array}$ & ,873 & ,646 \\
\hline & $\begin{array}{l}\text { Контроль } \\
\text { экспрессии }\end{array}$ & 1,174 &, 556 \\
\hline & $\begin{array}{c}\text { Межличностный } \\
\text { эмоциональный } \\
\text { интеллект }\end{array}$ & 6,362 & ,042 \\
\hline & $\begin{array}{c}\text { Внутриличностный } \\
\text { эмоциональный } \\
\text { интеллект }\end{array}$ & 3,121 & ,210 \\
\hline & Понимание эмоций & 9,483 & ,009 \\
\hline & $\begin{array}{c}\text { Управление } \\
\text { эмоциями }\end{array}$ & 1,466 & ,481 \\
\hline & $\begin{array}{c}\text { Общий уровень } \\
\text { эмоционального } \\
\text { интеллекта }\end{array}$ & 5,134 & ,077 \\
\hline
\end{tabular}

* жирным отмечены значимые различия

Установлены различия по шкалам методики ЭмИн Д.В. Люсина. Полученные данные позволяют утверждать, что работники со стажем работы от 3 лет до 10 лет в меньшей степени проявляют компетентность в понимании эмоций как чужих, так и своих. Они также характеризуются сниженным внутриличностным эмоциональным интеллектом.

Связь профессионального выгорания и эмоционального интеллекта у работников с разным стажем профессиональной деятельности

В (табл. 3) и на рисунках 3-5 отражены результаты исследования связи профессионального выгорания и эмоционального интеллекта у работников с разным стажем работы. 
Таблица 3

Результаты исследования связи профессионального выгорания и эмоционального интеллекта работников с разным стажем работы

\begin{tabular}{|c|c|c|c|c|}
\hline \multirow[b]{2}{*}{$\begin{array}{c}\text { Субшкалы } \\
\text { эмоционального } \\
\text { интеллекта }\end{array}$} & \multicolumn{3}{|c|}{ Показатели профессионального выгорания } & \multirow[b]{2}{*}{$\begin{array}{l}\text { Стаж работы } \\
\text { воспитателей }\end{array}$} \\
\hline & $\begin{array}{c}\text { Эмоциональное } \\
\text { истощение }\end{array}$ & Деперсонализация & $\begin{array}{c}\text { Редукция } \\
\text { професси- } \\
\text { ональных } \\
\text { достижений }\end{array}$ & \\
\hline \multirow{3}{*}{$\begin{array}{c}\text { Понимание чужих } \\
\text { эмоций }\end{array}$} & $r_{s}=-, 317$ & $\mathrm{r}_{\mathrm{s}}=-, 418^{*}$ & $\mathrm{r}_{\mathrm{s}}=, 654 * *$ & 0,5-3 года \\
\hline & $r_{s}=-, 120$ & $r_{s}=-, 295$ & $\mathrm{r}_{\mathrm{s}}=, 863 * *$ & 3-10 лет \\
\hline & $\mathrm{r}_{\mathrm{s}}=-, 515^{*}$ & $\mathrm{r}_{\mathrm{s}}=-, 537 * *$ & $\mathrm{r}_{\mathrm{s}}=, 819 * *$ & Более 10 лет \\
\hline \multirow{3}{*}{$\begin{array}{c}\text { Управление } \\
\text { чужими эмоциями }\end{array}$} & $\mathrm{r}_{\mathrm{s}}=, 213$ & $\mathrm{r}_{\mathrm{s}}=-, 451^{*}$ & $\mathrm{r}_{\mathrm{s}}=, 620 * *$ & 0,5-3 года \\
\hline & $\mathrm{r}_{\mathrm{s}}=-, 336$ & $\mathrm{r}_{\mathrm{s}}=-, 452$ & $\mathrm{r}_{\mathrm{s}}=, 257$ & 3-10 лет \\
\hline & $\mathrm{r}_{\mathrm{s}}=-, 574 * *$ & $\mathrm{r}_{\mathrm{s}}=-, 502 *$ & $\mathrm{r}_{\mathrm{s}}=, 659 * *$ & Более 10 лет \\
\hline \multirow{3}{*}{$\begin{array}{c}\text { Понимание своих } \\
\text { эмоций }\end{array}$} & $r_{s}=-, 291$ & $r_{\mathrm{s}}=-482 *$ & $\mathrm{r}_{\mathrm{s}}=, 840 * *$ & 0,5-3 года \\
\hline & $\mathrm{r}_{\mathrm{s}}=, 123$ & $r_{s}=-, 019$ & $r_{s}=, 290$ & 3-10 лет \\
\hline & $\mathrm{r}_{\mathrm{s}}=, 489 *$ & $\mathrm{r}_{\mathrm{s}}=-, 502 *$ & $\mathrm{r}_{\mathrm{s}}=, 461^{*}$ & Более 10 лет \\
\hline \multirow{3}{*}{$\begin{array}{c}\text { Управление } \\
\text { своими эмоциями }\end{array}$} & $\mathrm{r}_{\mathrm{s}}=-, 524 * *$ & $\mathrm{r}_{\mathrm{s}}=-, 584 * *$ & $\mathrm{r}_{\mathrm{s}}=, 683 * *$ & 0,5-3 года \\
\hline & $\mathrm{r}_{\mathrm{s}}=-, 252$ & $\mathrm{r}_{\mathrm{s}}=-, 421$ & $\mathrm{r}_{\mathrm{s}}=, 721 * *$ & 3-10 лет \\
\hline & $r_{s}=-, 666 * *$ & $\mathrm{r}_{\mathrm{s}}=-, 552 * *$ & $\mathrm{r}_{\mathrm{s}}=, 545^{* *}$ & Более 10 лет \\
\hline \multirow{3}{*}{$\begin{array}{c}\text { Контроль } \\
\text { экспрессии }\end{array}$} & $\mathrm{r}_{\mathrm{s}}=-, 420 *$ & $\mathrm{r}_{\mathrm{s}}=-, 497 * *$ & $\mathrm{r}_{\mathrm{s}}=, 397 *$ & 0,5-3 года \\
\hline & $\mathrm{r}_{\mathrm{s}}=-, 149$ & $r_{s}=-, 274$ & $\mathrm{r}_{\mathrm{s}}=, 331$ & 3-10 лет \\
\hline & $r_{s}=-, 375$ & $r_{s}=-, 398$ & $r_{\mathrm{s}}=, 359$ & Более 10 лет \\
\hline \multirow{3}{*}{$\begin{array}{c}\text { Межличностный } \\
\text { эмоциональный } \\
\text { интеллект }\end{array}$} & $r_{s}=-, 243$ & $\mathrm{r}_{\mathrm{s}}=-, 414 *$ & $\mathrm{r}_{\mathrm{s}}=, 697 * *$ & 0,5-3 года \\
\hline & $\mathrm{r}_{\mathrm{s}}=-, 236$ & $\mathrm{r}_{\mathrm{s}}=-, 389$ & $\mathrm{r}_{\mathrm{s}}=, 795^{* *}$ & 3-10 лет \\
\hline & $\mathrm{r}_{\mathrm{s}}=-, 575^{* *}$ & $\mathrm{r}_{\mathrm{s}}=-, 543 * *$ & $\mathrm{r}_{\mathrm{s}}=, 778 * *$ & Более 10 лет \\
\hline \multirow{3}{*}{$\begin{array}{c}\text { Внутриличностный } \\
\text { эмоциональный } \\
\text { интеллект }\end{array}$} & $\mathrm{r}_{\mathrm{s}}=-, 432^{*}$ & $\mathrm{r}_{\mathrm{s}}=-, 584 * *$ & $\mathrm{r}_{\mathrm{s}}=, 782 * *$ & 0,5-3 года \\
\hline & $\mathrm{r}_{\mathrm{s}}=, 030$ & $r_{s}=-, 190$ & $\mathrm{r}_{\mathrm{s}}=, 481^{*}$ & 3-10 лет \\
\hline & $\mathrm{r}_{\mathrm{s}}=-, 599 * *$ & $\mathrm{r}_{\mathrm{s}}=-,-527 * *$ & $\mathrm{r}_{\mathrm{s}}=, 488^{*}$ & Более 10 лет \\
\hline \multirow{3}{*}{ Понимание эмоций } & $\mathrm{r}_{\mathrm{s}}=-, 252$ & $\mathrm{r}_{\mathrm{s}}=-, 430^{*}$ & $\mathrm{r}_{\mathrm{s}}=, 819 * *$ & 0,5-3 года \\
\hline & $\mathrm{r}_{\mathrm{s}}=-, 0,55$ & $\mathrm{r}_{\mathrm{s}}=-, 253$ & $\mathrm{r}_{\mathrm{s}}=, 829 * *$ & 3-10 лет \\
\hline & $\mathrm{r}_{\mathrm{s}}=-, 530 *$ & $\mathrm{r}_{\mathrm{s}}=-, 555^{* *}$ & $\mathrm{r}_{\mathrm{s}}=, 732 * *$ & Более 10 лет \\
\hline \multirow{3}{*}{$\begin{array}{c}\text { Управление } \\
\text { эмоциями }\end{array}$} & $\mathrm{r}_{\mathrm{s}}=-, 411^{*}$ & $\mathrm{r}_{\mathrm{s}}=-, 577 * *$ & $\mathrm{r}_{\mathrm{s}}=, 641 * *$ & 0,5-3 года \\
\hline & $\mathrm{r}_{\mathrm{s}}=-, 379$ & $\mathrm{r}_{\mathrm{s}}=-, 468^{*}$ & $\mathrm{r}_{\mathrm{s}}=, 539^{*}$ & 3-10 лет \\
\hline & $r_{s}=-, 625 * *$ & $\mathrm{r}_{\mathrm{s}}=-, 521^{*}$ & $\mathrm{r}_{\mathrm{s}}=, 548 * *$ & Более 10 лет \\
\hline \multirow{3}{*}{$\begin{array}{c}\text { Общий уровень } \\
\text { эмоционального } \\
\text { интеллекта }\end{array}$} & $r_{s}=-, 331$ & $\mathrm{r}_{\mathrm{s}}=-, 511 * *$ & $\mathrm{r}_{\mathrm{s}}=, 773 * *$ & 0,5-3 года \\
\hline & $\mathrm{r}_{\mathrm{s}}=-, 199$ & $\mathrm{r}_{\mathrm{s}}=-, 350$ & $\mathrm{r}_{\mathrm{s}}=, 749 * *$ & 3-10 лет \\
\hline & $\mathrm{r}_{\mathrm{s}}=-, 632 * *$ & $\mathrm{r}_{\mathrm{s}}=-, 579 * *$ & $\mathrm{r}_{\mathrm{s}}=, 600 * *$ & Более 10 лет \\
\hline
\end{tabular}

Примечание: $* \mathrm{p}<0.05, * * \mathrm{p}<0.01$

Из (табл. 3) мы видим, что существуют взаимосвязи между профессиональным выгоранием и показателями эмоционального интеллекта в 
группах работников с разным стажем работы. На (рис. 3-5) наглядно представлены плеяды связей. Следует отметить, что структура связей в группах имеет видимые различия. Так в группе 2 у работников со стажем работы от 3 до 10 лет выявлено наименьшее количество связей между показателями профессионального выгорания и шкалами эмоционального интеллекта. В группах 1 (стаж работы от 0,5 до 3 лет работы) и 3 (стаж работы более 10 лет) выявлено более, чем в три раза больше связей. Однако необходимо отметить, что во всех группа показатели профессионального выгорания Эмоциональное истощение и Деперсонализация имеют отрицательные связи со шкалами Эмоционального интеллекта, показатель Редукция профессионализма имеет положительные связи со шкалами эмоционального интеллекта.

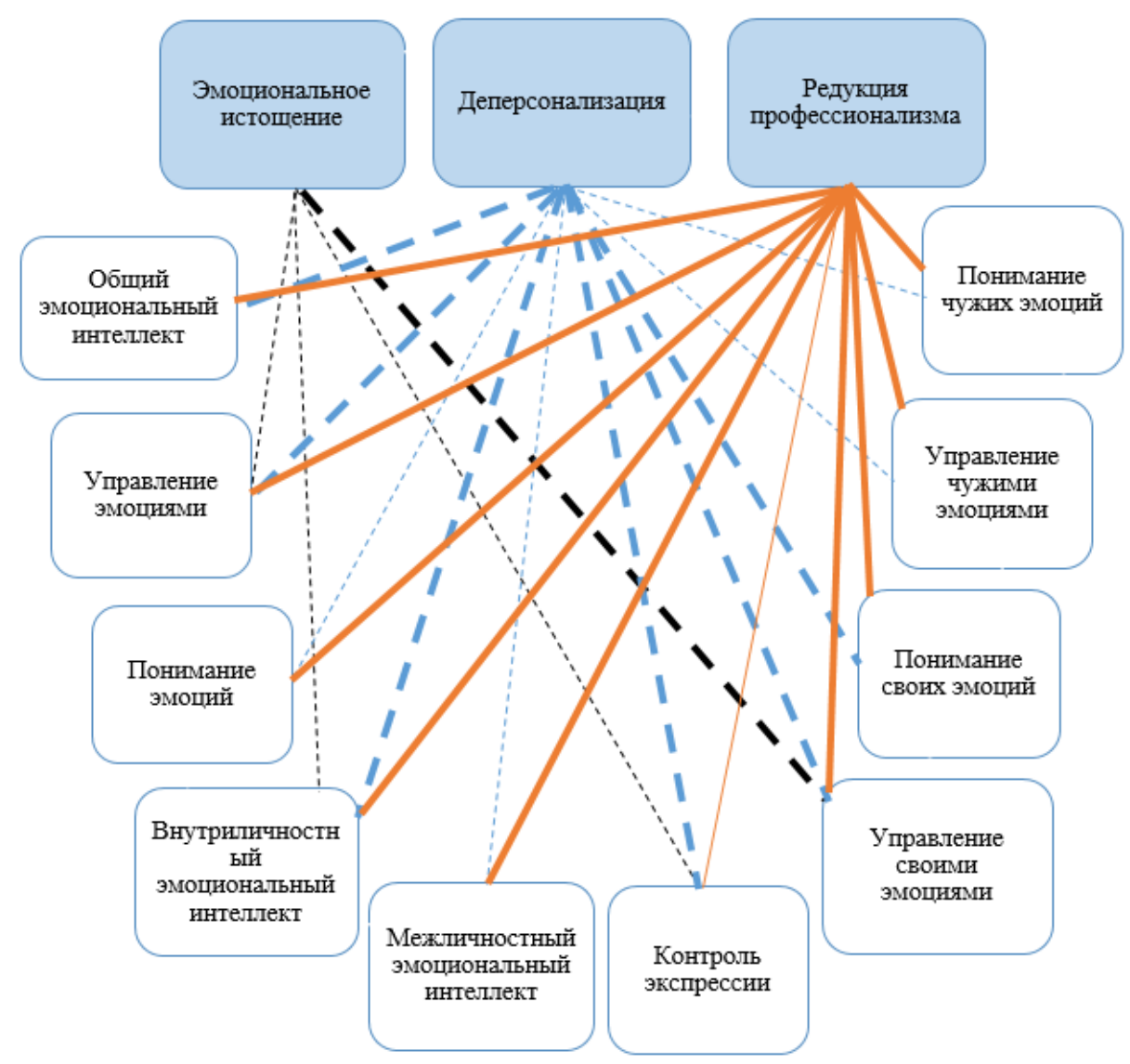

Рис. 3. Связь профессионального выгорания и эмоционального интеллекта в группе работников со стажем работы от 0,5 до 3 лет

Примечания:

связь, - обратная сильная связь 
В группе 1 (воспитатели со стажем работы от 0,5 до 3 лет работы) все шкалы эмоционального интеллекта имеют связи с показателями профессионального выгорания. В данной структуре можно отметить, что наиболее ключевым является шкала Управление своими эмоциями (имеет сильные связи со всеми показателями профессионального выгорания). Выявлено, что показатель Эмоциональное истощение отрицательно связано со шкалами Управление своими эмоциями, Контроль экспрессии, Внутриличностный эмоциональный интеллект, Управление эмоциями. Показатель Деперсонализация отрицательно связан со всеми шкалами методики ЭмИн Люсина. Данные результаты говорят о том, что чем выше чувство отчуждения и «психическая анестезия», тем ниже способность к пониманию как своих, так и чужих эмоций и управлению ими. Показатель Редукция профессиональных достижений связано со всеми шкалами Эмоционального интеллекта. Чем ниже удовлетворенности педагога собой как личностью и как профессионалом, тем ниже способность к пониманию и управлению эмоциями, тем ниже эмоциональный интеллект.

Таким образом, в группе работников со стажем работы до трех лет сложилась сложная структура связей показателей профессионального выгорания и эмоционального интеллекта. Это говорит о том, что для работников этой группы при повышении уровня профессионального выгорания снижаются показатели компетентности эмоционального интеллекта. Эмоциональное истощение приводит к снижению чувствительности собственных эмоций, контролю экспрессии, пониманию и идентификации собственных переживаний. Чем чаще работник ощущает «пустоту» и утрату собственной самости, испытывает неудовлетворенность своими профессиональными качествами, ищет пути снижения нагрузки выполнения своих обязанностей, тем ниже у него наблюдаются проявления компетентности эмоционального интеллекта, выражающиеся в нечувствительности, эмоциональной «анестезии», черствости и бесчувственности. Можно предположить, что именно профессиональное выгорание становится фактором, негативно влияющим на эмоциональный интеллект работников со стажем работы до 3 лет.

Структура связей между показателями профессионального выгорания и эмоционального интеллекта работников со стажем работы от трех лет до 10 лет качественно и количественно отличается. Результаты исследования связей представлены на (рис. 4). 


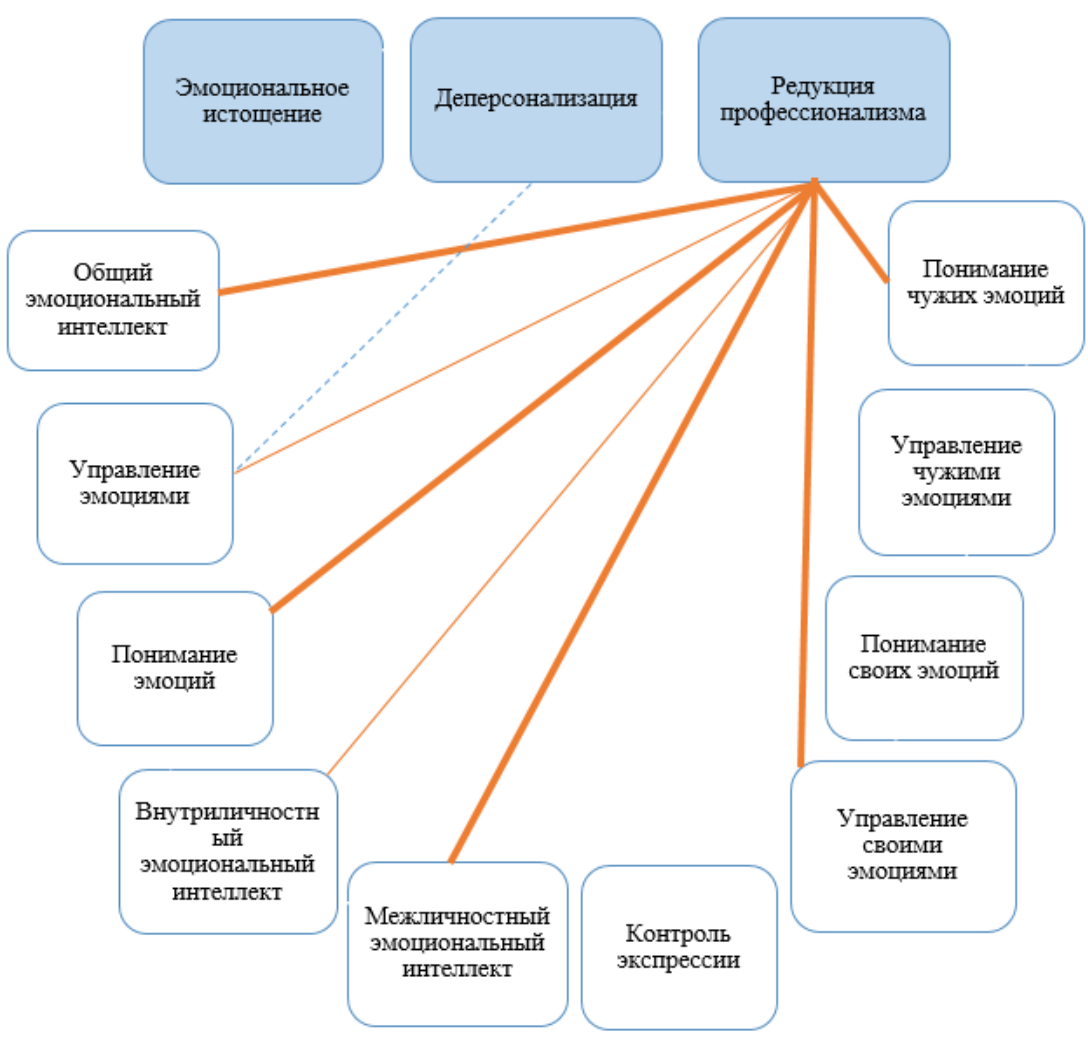

Рис. 4. Связь профессионального выгорания и эмоционального интеллекта в группе работников со стажем работы от 3 до 10 лет

Прнмечания: — прямая слабая связь, прямая снльная связь, =-z- обратная слабая связь, $=$ обратная сильная связь

В структуре связей между эмоциональным интеллектом и профессиональным выгоранием работников со стажем от 3 до 10 лет выявлено, что отсутствуют связи между показателем профессионального выгорания Эмоциональное истощение и шкалами эмоционального интеллекта. Выявлена слабая отрицательная связь между показателем Деперсониализация и шкалой Управление эмоциями. Установлены положительные связи между показателем Редукция профессионализма и шкалами Понимание чужих эмоций, Управление своими эмоциями, Межличностный эмоциональный интеллект, Внутриличностный эмоциональный интеллект, Понимание эмоций, Управление эмоциями, Общий эмоциональный интеллект. Не установлены взаимосвязи между шкалами ЭИ Управление чужими эмоциями, Понимание своих эмоций, Контроль экспрессии и показателями профессионального выгорания. Показатель Редукция профессиональных достижений является ключевым показателем оказывающий влияние на проявление способности к пониманию, 
идентификации и управлении эмоций. Шкала способности Управления эмоциями в данной структуре ЭИ работников со стажем работы от 3 до 10 лет имеет более высокий вес (установлены две связи Деперсонализация и Редукция профессионализма). Это говорит о том, что при повышении чувства отстраненности от деятельности и субъектов образования, увеличения неудовлетворенности собой как личностью и профессионалом снижается способность к управлению эмоций как своих, так и чужих.

В целом структура связей профессионального выгорания и эмоционального интеллекта работников со стажем работы от 3 до 10 лет качественно отличается от структуры связей работников со стажем работы до 3 лет и более 10 лет. Можно предположить, что показатель Редукция профессионализма оказывает влияние на эмоциональный интеллект работников. Однако есть вероятность, что именно в этой группе присутствуют другие факторы, оказывающие воздействия как на сформированность эмоционального интеллекта, так и на профессиональное выгорание.

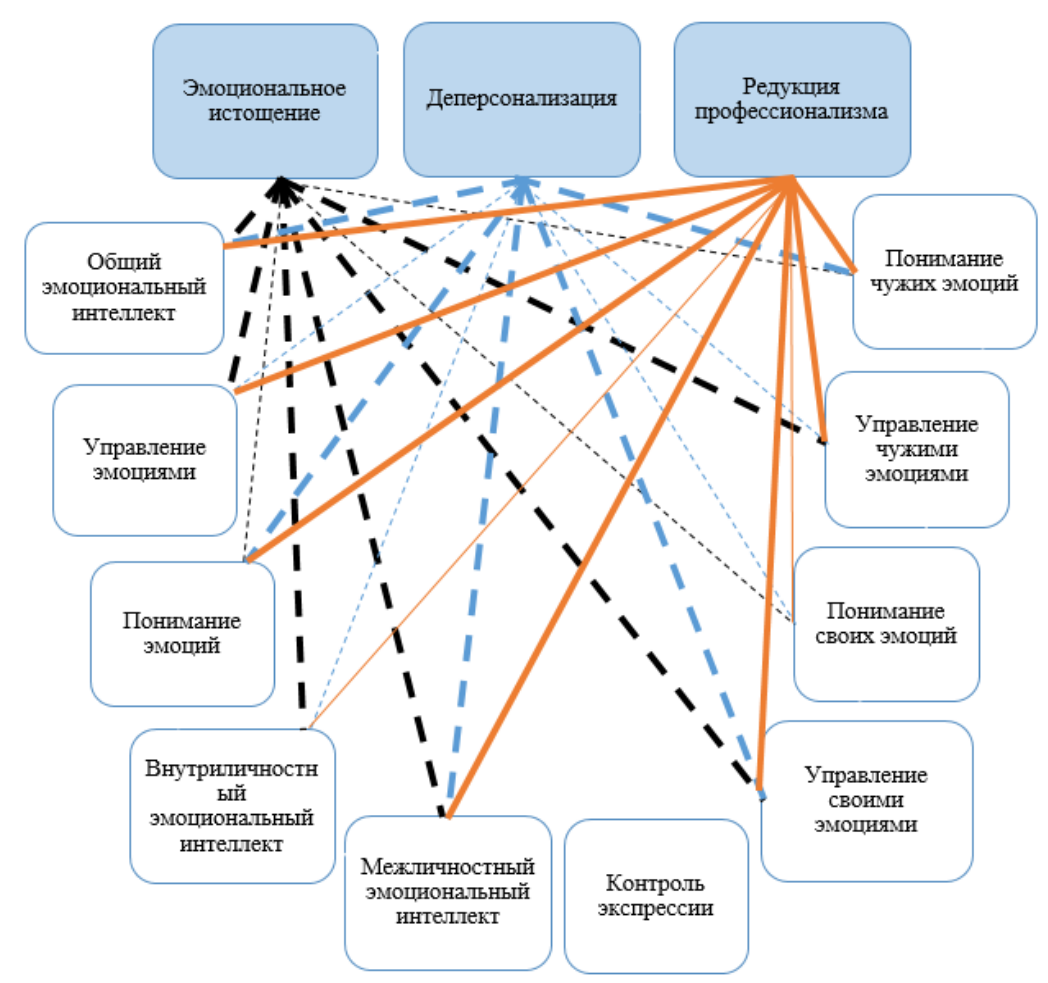

Рис. 5. Связь профессионального выгорания и эмоционального интеллекта в группе работников со стажем работы более 10 лет

Прнмечания: — прямая слабая связь, прямая сильная связь, =-こ- обратная слабая связь, $=$ обратная сильная связь 
В группе 3 - работников со стажем работы более 10 лет выявлены взаимосвязи практически всех шкал ЭИ (кроме шкалы Контроль экспрессии) с показателями профессионального выгорания. Наиболее сильные веса имеют показатель Редукция профессионализма имеет самый высокий вес из показателей профессионального выгорания (7 сильных связей, 2 слабые) и шкалы эмоционального интеллекта Управление своими эмоциями, Межличностный эмоциональный интеллект, Общий эмоциональный интеллект (наличие сильных связей со всеми показателями методики Профессиональное выгорание). Полученные результаты говорят о том, что при повышении уровня профессионального выгорания снижается способность распознавать и идентифицировать эмоции, понимать причины, вызвавшие данную эмоцию, и следствия, к которым она приведёт; снижается контроль интенсивности эмоций и способности контролировать внешнее выражение эмоций. Необходимо заметить, что структура связей в данной группе работников является сложной и показатели профессионального выгорания и эмоционального интеллекта оказывают влияние друг на друга.

Обсуждение результатов. Полученные данные не соответствуют результатам, полученным К. Жегловой. В ее исследовании определена отрицательная взаимосвязь между стажем работы оператора и редукцией профессиональных достижений (Жеглова, 2007), что свидетельствует об ограниченности взаимосвязи компонентов профессионального выгорания и стажа [5]. Однако, данные результаты не противоречат результатам исследованиям Е.Н. Бочкаревой выявившей положительные связи компонентов эмоционального интеллекта сотрудников и руководителей контактного центра с показателем эмоционального выгорания Редукция профессиональных достижений. Однако, автор приходит к заключению, что показатель Эмоциональное истощение является ключевым фактором, влияющим на эмоциональный интеллект [2]. В нашем исследовании установлено, что показатель Редукция профессиональных достижений имеет больший вес влияния на эмоциональный интеллект педагога.

Выводы

Установлено, что у большинства работников средний уровень профессионального выгорания. Однако, чем выше стаж работы, тем чаще у работников отмечается повышение Эмоционального истощения и Деперсонализации. Установлено, что работники со стажем работы более 10 лет в меньшей степени склонны к проявлению Редукции 
профессионализма, т.е. они в целом удовлетворены своими профессиональными и личностными качествами, в отличии от работников со стажем работы от 3 до 10 лет.

Выявлено, что эмоциональный интеллект в большей степени развит у работников со стажем работы более 10 лет, менее всего развиты способности понимания, идентификации и регуляции эмоций у работников со стажем работы от 3 до 10 лет.

Независимо от стажа работы, компетентность эмоционального интеллекта и профессиональное выгорание взаимосвязаны. Однако присутствуют некоторые специфические особенности структуры связей между профессиональным выгоранием и эмоциональным интеллектом в группах педагогов с разным стажем работы. Наиболее сложная структура связей профессионального выгорания и эмоционального интеллекта выявлена в группе педагогов со стажем работы более 10 лет. Менее структурированная система связей выявлена во 2 группе исследуемых. Возможно в период от 3 до 10 лет профессионального становления на выгорание и эмоциональный интеллект педагогов оказывают иные факторы и стимулы.

В группе работников со стажем работы от 0,5 до 3 лет наибольший вес имеет показатель Редукция профессионализма. Воспитатели, испытывающие неудовлетворенность своей профессиональной компетентностью, характеризуются низким уровнем эмоционального интеллекта. С повышением уровня Эмоционального истощения, Деперсонализации и Редукции профессиональных достижений у работников наблюдается снижение компетентности в понимании и управлении собственных эмоций, контролировании экспрессии и невербального поведения. Снижение внутриличностного эмоционального интеллекта и способности к управлению своими и чужими эмоциями вызваны синдромом деперсонализации работников, которая проявляется в негативном отношении к воспитанникам и коллегам, циничности, автоматическом «функционировании» и избегании различных нагрузок. Работник, у которого наблюдается хроническая усталость, сниженное настроение, расстройства сна, диффузные телесные недуги и болезни характеризуется сниженной способностью управлять своими и чужими эмоциями, понимать и идентифицировать эмоции, регулировать и контролировать их, адекватно выражать их.

У работников со стажем работы от 3 до 10 лет установлен средний уровень профессионального выгорания и значительно ниже проявление 
показателя Редукция профессиональных достижений, чем у работников со стажем работы более 10 лет. Структура связей профессионального выгорания и эмоционального интеллекта позволяют говорить, что ведущим является показатель Редукция профессиональных достижений. Чем чаще работник негативно оценивает свою профессиональную компетентность и результаты труда, тем сложнее ему понимать и идентифицировать свои эмоции и переживания других.

В группе работников со стажем работы более 10 лет синдром Редукция профессионализма имеет наибольшее влияние на эмоциональный интеллект педагогов. Испытываемые негативные эмоции в отношении себя как профессионала, отрицательная оценка своего труда приводит к снижению эмоционального интеллекта.

Анализ профессионального выгорания работников ДОУ показал, что Редукция профессиональных достижений - это компонент выгорания, который в сравнении с другими компонентами выражен наиболее сильно. Это отражает степень неудовлетворенности педагогов собой как личностью и профессионалом. Деперсонализация, которую часто определяют как попытку сотрудника отстраниться от работы, чтобы снизить собственный уровень стресса, и эмоциональное истощение распространены в меньшей степени. Таким образом, профилактика профессионального выгорания у работников ДОУ должна быть в первую очередь направлена на коррекцию редукции профессиональных достижений, эмоционального истощения и предотвращение роста деперсонализации.

Результаты исследования могут использоваться в работе педагогов-психологов дошкольных учреждений с целью разработки профилактических мероприятий эмоционального выгорания воспитателей посредством развития у сотрудников эмоционально-личностной сферы и компетентности эмоционального интеллекта.

\section{Список литературы}

1. Бойко В.В. Энергия эмоций. 2-е изд. СПб.: Питер; 2004.

2. Бочкарева Е.Н. Взаимосвязь профессионального выгорания и эмоционального интеллекта сотрудников контактного центра// Психология. Журнал Высшей школы экономики. 2016. Т. 13. № 3. С. 576-587.

3. Водопьянова Н.Е. Психодиагностика стресса. СПб.: Питер, 2013. 
4. Гоулман Д. Эмоциональный интеллект. пер. с англ. А.П. Исаевой. М.: АСТ: АСТ Москва: Хранитель, 2012. 478 с.

5. Жеглова К.Ю. Особенности динамики формирования психического выгорания в профессии оператора телекоммуникационной связи // автореф. канд. дисс., Ярославский государственный университет им. П.Г. Демидова, Ярославль, 2007.

6. Люсин Д.В. Современные представления об эмоциональном интеллекте / В кн. Д.В. Люсин и Д.В. Ушаков (ред.), Социальный интеллект: Теория, измерение, исследования. М.: Изд-во «Институт психологии РАН», 2004, c. 29-36.

7. Люсин Д.В. Опросник на эмоциональный интеллект ЭмИн: новые психометрические данные / В кн. Д.В. Люсин и Д.В. Ушаков (ред.), Социальный и эмоциональный интеллект: от моделей к измерениям. М.: Изд-во «Институт психологии РАН», 2009, с. 264-278.

8. Мальцева Н.В. Проявления синдрома психического выгорания в процессе профессионализации учителя в зависимости от возраста и стажа работы // автореф. канд. дисс., Российский государственный рофессионально-педагогический университет, Екатеринбург, 2005.

9. Перевезенцева Н.Л. Мальгрэм Е.В. Репрезентация эмоционального интеллекта у студентов гуманитарных специальностей / Актуальные проблемы психолого-педагогического и медико-социального сопровождения высшего образования: интеграция науки и практики. Материалы IV межрегиональной, с международным участием научно-практической конференции. Хабаровск, Изд-во: «Дальневосточный государственный гуманитарный университет», 2016. С. 95-98.

10. Солодкова Т.И. Эмоциональный интеллект как личностный ресурс преодоления синдрома выгорания и его развитие у педагогов // Автореф. канд. дисс., Восточно-Сибирская государственная академия образования, Иркутск, 2011.

11. Феофанов В.Н. Психическое выгорание учителей специальных (коррекционных) школ как фактор психологического здоровья учащихся с отклонениями в развитии // Психология и педагогика, теория и методика обучения, 2008, 466-475.

12. Юрьева Л.Н. Профессиональное выгорание у медицинских работников: формирование, профилактика, коррекция. Киев: Сфера; 2004. 
13. Maslach C, Jackson SE. The Maslach Burn-Out Inventory Mannual (2nd. ed.). Palo Alto, CA: Consulting Psychologist Press; 1986.

14. McFarland R.G., Rode J.C., \& Shervani T.A. A contingency model of emotional intelligence in professional selling. Journal of the Academy of Marketing Science. Advance on-line publication. 2015. http://doi.org/ 10.1007/s11747-0150435-8.

15. Pines A, Aronson E. Career burnout: causes and cures. A Pines, New York: Free Press; 1988.

16. Freudenberger HJ. Staff burn-out. Journal of Social Issues. 1974;30:159166. https://doi.org/10.1111/j.1540-4560.1974.tb00706.x.

(C) А.С. Крючкова, Н.Г. Дзюбина, 2021 